\title{
Application of ARIZ to Social Issues: Case of ICT Device Addiction in Pre-teen Children in India
}

\author{
Bala Ramadurai ${ }^{1}$ and Muralidharan Loganathan ${ }^{2}$ [0000-0001-5436-5791] \\ ${ }^{1}$ Independent innovation consultant, Pune, India \\ bala@asu.edu \\ ${ }^{2}$ Department of Management Studies, Indian Institute of Science, Bangalore, India \\ muralidharanl@gmail.com
}

\begin{abstract}
While information and communication technology (ICT) has facilitated the exploration of online content through applications and games, there has been a significant increase in research on the pathological use of ICT devices, particularly smart phones. India is home to a growing number of people using ICT devices; many of these people were born in the 2000s. This scenario poses significant challenges in development and parental control. We are contributing to the literature on the application of TRIZ to social issues by examining the issue of addiction to ICT devices among pre-teenage or gradeschool children in India. We adopt a case-based approach to studying ICT device usage and apply TRIZ-based methods to solve for both exploration and parental control. We present a set of innovative solution concepts for further development. Further, we propose potential developmental models that can be adopted by device manufacturers, considering the recent activism in the area.
\end{abstract}

Keywords: ICT, addiction, development, parental control, India, mobile devices, children, pre-teen, ARIZ-85c, TRIZ

\section{Introduction}

Studies have reported a global increase in the use of digital technology or, broadly, of ICT devices among young children (Bavelier et al.,2010). While such an increase in the use of ICT devices provides opportunities for better learning and playing engagements, pedagogy for young children needs to be re-conceptualized (Palaiologou, 2016). Such engagements are known to consume a significant proportion of time and can lead to pathological addiction to digital media and gaming (Block, 2008). Further, existing literature acknowledges that there is very little understanding of the disruptive effects of such technology use on the ability of children to function normally in society (Bavelier et al., 2010; Ko, Yen, Yen, Chen, \& Chen, 2012). This type of technology usage has detrimental effects on creative imagination, visual memory, and attention span among children (Kumari \& Ahuja, 2010). Thus, parental concerns about the uncontrolled use of ICT devices appear to be valid (Sergi, Gatewood, Elder, \& Xu, 2017).

The clinical approach to technology addiction and research is fraught with difficulties even in classifying between psychiatric disorders and pathological use. In 
general, most treatments for such pathological use consider the subject (the person addicted) as the focus of the treatment, and it is acknowledged that most of these treatments are risky and ineffective (Block, 2008). Hence, in our opinion, this approach is myopic. This area of addiction also witnesses general concern and activism to force or lobby Internet and technology companies to become more responsible (Kawa, 2018; Tiku, 2018).

We propose a different approach-focusing on the critical role of the object of addiction, viz. the technology, and exploring system-level solutions for this important issue of device addiction (Shaffer, 1996). This approach can result in less risky and more effective solutions that simultaneously address child engagement and parental control. We employ TRIZ-based methods that are equipped to solve such system-level contradictions by utilizing a structured algorithm (Altshuller, Shulyak, \& Rodman, 1999).

The remainder of this paper is organized into three sections. In Section 2, we present a general literature review of clinical approaches to technology addiction and the application of TRIZ-based methods to social and non-technical problems. In Section 3, we describe our method and approach to solve the challenge by applying TRIZ and other methods, and in section 4, we explain the resulting solution concept. Finally, we discuss some implications of the solution, the direction of future work, and ways in which we can approach stakeholders to adopt such solutions to address this growing global concern.

\section{$2 \quad$ Literature review}

The literature review for our research motivation is distinctly split across two bodies of knowledge concerning: 1) the application of TRIZ, which is primarily an engineering solution methodology, to social and behavioral issues; and 2) the pathological use of technologies by children globally, and the current assessment and treatment approaches.

\subsection{Application of TRIZ in social sciences}

Historically, TRIZ literature has not followed the typical paths of theory validation. While the applications of TRIZ to engineering or industrial problems are acknowledged, the ambitious goals of the theory remain to be tested across varied fields of application (Chechurin \& Borgianni, 2016). Business- and management-related applications of TRIZ-based methods are only a recent addition, while applications in social sciences are few and far between (Domb 2003, Chai et al. 2005, Chechurin, 2016; Schut, 2016). The reasons for the limited application of TRIZ in other fields could be traced to discontinuous efforts in building theory for business applications and the lack of wider diffusion to non-technical fields (few examples can be seen in Zlotin et al., 1999).

A review of literature of TRIZ reveals the broad range of applications across several fields, and we note that design-related outcomes from these applications are popular (Sharma, Khanna, \& Bhatnagar, 2016). Schut (2016) acknowledges that the application of TRIZ to non-technical and social fields is possible, with some limitations. These 
limitations range from approaching social problems with an engineering view while it may not even be applicable in the context, to having many stakeholders in a problem context. Further, the application of TRIZ-based methods can be challenging because of the significant investment of time needed to understand the theory, the lack of structured instructions to learn TRIZ, the perceived complexity of the methods, and other cultural or language issues. These difficulties have manifested in the lack of development and diffusion of the methodology, which in turn has reduced the application to non-technical domains and varied research directions (Chechurin \& Borgianni, 2016; Ilevbare, Probert, \& Phaal, 2013).

We propose addressing these issues and limitations by: 1) limiting the number of stakeholders, and 2) applying TRIZ-based methods to obtain quasi-technical solutions in the social-problem context.

\subsection{Children and technology engagement}

Since the advent and easy access of Internet, researchers are increasingly studying problematic Internet use that results in negative effects on social and emotional functioning (Shaffer et al. 2000, Shapira et al., 2003). This problem has been more pronounced in the case of adolescents and young children who are more "digitally fluent" and experience a negative impact on learning engagements (Bozkurt, Coskun, Ayaydin, Adak, \& Zoroglu, 2013; Palaiologou, 2016; Kuss et al., 2014). Existing literature in the area considers both cross-sectional and longitudinal data from empirical studies across the globe. In general, these studies identify factors that affect such pathological use, develop scales to characterize the use, explore the negative effects of such use across behavioral and social dimensions, and finally, propose clinical approaches to this condition (Kuss et al., 2014). Kuss et al. (2014) identify 4 factors affecting Internet addiction, as shown in Fig. 1. viz. sociodemographic variables include age, gender, background, education, and income; internet use variables include age of exposure to internet, frequency and duration of use, type of use like entertainment or gaming, parental guidance among others; pyscho-social factors include mood regulation, satisfaction, loneliness among other internal/social characteristics of the user; whereas the comorbid symptoms include additional substance abuse, and other symptoms like ADHD, depression, aggressive behaviours, that occur along with the addiction.

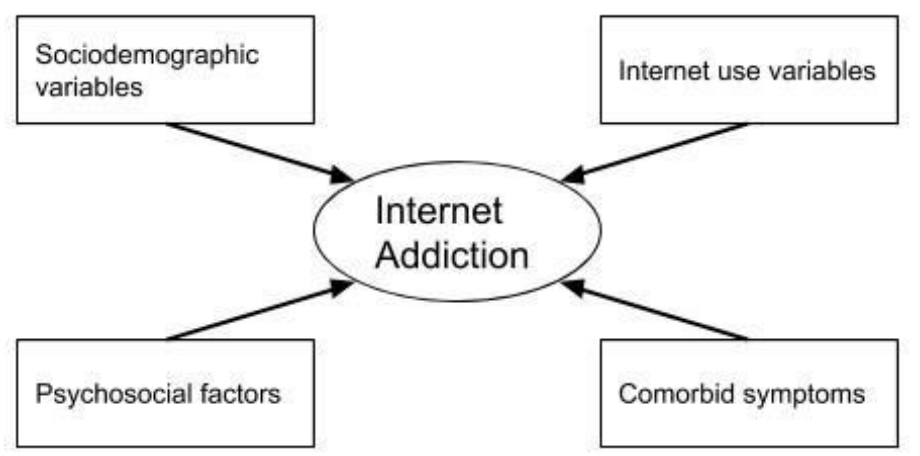


Fig. 1. Factors associated with Internet addiction. Source: (Kuss et al., 2014)

From among the 4 factors in Fig. 1, we are interested in the Internet use variables (Kuss et al., 2014). Specifically, from among the Internet use variables, the aspect that appears to be most relevant to our study is the role of family in providing a secure and supportive environment or in not providing such an environment, and the corresponding effect on internet addiction (Lips et al., 2017). Such a study in not available in existing literature.

The diagnosis and assessment of Internet addiction does not have a gold standard or nosological precision. Existing approaches for treatment consider only the subject and ignore the objects of addiction. This is important, because the internet defies a general characterization beyond links and experiences; thus, the object of addiction is markedly different from specific substances such as heroin or specific activities such as gambling (Shaffer, 1996). Further, the treatment approaches for internet addiction are risky and ineffective, considering several effects including relapse (Block, 2008). On the other hand, working with object-centric approaches is safer and allows multiple types of alternatives to address such an addiction. Such an approach is also a gap in literature that we address.

Thus, the gaps in literature described in this section can potentially be addressed by simultaneously considering the object of addiction and the role of family, particularly of the parents in providing an environment conducive to the modification of use-related factors (Kuss et al., 2014).

\section{Methodology and approach}

We chose ARIZ-85c as the methodology for solving the ICT device addiction issue among children. ARIZ-85c consists of 9 parts; in our study, we focused on the first 3 parts. In addition to ARIZ-85c, we included a "Part-0" (consisting of 9 steps) from an earlier version of ARIZ-ARIZ-85a (Altshuller, 1987; Kucharavy, 2006). This additional part was included to augment our understanding of the problem by analyzing the initial situation. While we have provided the application details of the first 4 parts preserving brevity of this article, readers are encouraged to follow through the entire ARIZ algorithm to completion for their specific applications.

The steps in Part- 0 distilled the problem to a contradiction that had to then be solved by using the first 3 parts of ARIZ-85c, described below (the number of steps in each part is written in parentheses):

1. Part-1: Analyzing the problem (7 steps)

2. Part-2: Analyzing the problem model (3 steps)

3. Part-3: Defining the ideal final result (IFR) and physical contradiction (PhC) (7 steps)

\subsection{Part-0: Analysis of the Initial Situation}


We performed Part-0 prior to the main problem analysis to ascertain the context of the problem situation. Prior to Part-0, we defined the system operator, which describes the environment around the problem scenario.

System operator.

The system operator (shown in Table 1) describes the environment around the child who is playing mobile games on a mobile device. The time frame of reference was chosen to be 5 years.

Table 1. System operator

\begin{tabular}{|l|l|l|l|}
\hline & 5 years ago & Present & 5 years later \\
\hline $\begin{array}{l}\text { Supersystem } \\
\text { (Environment) }\end{array}$ & Family & Friends & Interest Groups \\
\hline System & Computer Games & Mobile Games & Virtual World Games \\
\hline $\begin{array}{l}\text { Subsystem } \\
\text { (Components) }\end{array}$ & $\begin{array}{l}\text { Eyes, Mind, PC, } \\
\text { Mouse, Offline } \\
\text { Games }\end{array}$ & $\begin{array}{l}\text { Eyes, Mind, Device, } \\
\text { Thumbs, App, WiFi }\end{array}$ & $\begin{array}{l}\text { Eyes, Mind, Goggles, } \\
\text { Virtual / Augmented } \\
\text { reality Technology, } \\
\text { Gestures, WiMAX, } \\
\text { Dynamic App }\end{array}$ \\
\hline
\end{tabular}

The overall functionality of the system was: To entertain or engage the child outside of the school hours. (Point of view: child's parents)

The steps from Part- 0 are summarized in Table 2.

Table 2. Summary of the steps performed in Part- 0 and the corresponding learning from each step.

\begin{tabular}{|l|l|}
\hline \multicolumn{1}{|c|}{ Step } & \multicolumn{1}{|c|}{ Learning } \\
\hline $\begin{array}{l}\text { Step-1: Determine the } \\
\text { final goal of a solution }\end{array}$ & $\begin{array}{l}\text { We characterized the effort dedicated by the solvers, and the } \\
\text { impact to the end user, viz. the child using technology. We } \\
\text { determined potential benefits and harm that could be } \\
\text { produced by the use of technology. We included exploration } \\
\text { viz. time spent both online and offline. }\end{array}$ \\
\hline $\begin{array}{l}\text { Step-2: Investigate a } \\
\text { "bypass approach" }\end{array}$ & $\begin{array}{l}\text { "How might we reduce the mental and bodily strain on the } \\
\text { child?" and "In what way might we reduce the screen time } \\
\text { of a mobile device/app?" were the bypass problem } \\
\text { statements. }\end{array}$ \\
\hline
\end{tabular}




\begin{tabular}{|c|c|}
\hline $\begin{array}{l}\text { Step-3: Determine } \\
\text { which problem, the } \\
\text { original or the bypass, } \\
\text { makes the most sense } \\
\text { to solve }\end{array}$ & $\begin{array}{l}\text { We chose the following problem from the analysis in Step- } \\
2 \text { : } \\
\text { In what way might we control the nature of apps that are } \\
\text { downloaded? }\end{array}$ \\
\hline $\begin{array}{l}\text { Step-4: } \begin{array}{c}\text { Determine } \\
\text { the required }\end{array} \\
\text { quantitative } \\
\text { characteristics }\end{array}$ & $\begin{array}{l}\text { We analyzed characteristics such as addiction assessment, } \\
\text { parental/regulatory control, and nature and type of } \\
\text { applications that result in pathological use. } \\
\text { At a macroscopic level, we observed that an increase in } \\
\text { mobile usage included active usage of the internet and apps } \\
\text { across different types including video, gaming and social } \\
\text { networking. At a microscopic level, we observed a) the } \\
\text { proportion of parents preferring timebased restrictions, b) } \\
\text { various addiction scales, and c) the effects of regulatory } \\
\text { controls on controlling internet use. }\end{array}$ \\
\hline $\begin{array}{l}\text { Step-5: Increase the } \\
\text { required quantitative } \\
\text { characteristics by } \\
\text { considering the time for } \\
\text { implementing the } \\
\text { invention }\end{array}$ & $\begin{array}{l}\text { The population considered in our study includes children } \\
\text { between } 10 \text { and } 14 \text { years of age. We assumed that this } \\
\text { population may grow at an estimated rate of } 1 \% \text {, and hence, } \\
\text { we obtain an estimated target population size of } \\
\text { approximately } 635 \text { million in } 2019 \text { (Lips et al., 2017; United } \\
\text { Nations Department of Economic and } \\
\text { Social Affairs, 2017) }\end{array}$ \\
\hline $\begin{array}{l}\text { Step-6: Define the } \\
\text { requirements of the } \\
\text { specific conditions in } \\
\text { which the invention is } \\
\text { going to function }\end{array}$ & $\begin{array}{l}\text { Free to use, light impact on the device resources, and easy to } \\
\text { use or administer for the parents or children. }\end{array}$ \\
\hline $\begin{array}{l}\text { Step-7: Examine direct } \\
\text { application of inventive } \\
\text { standards }\end{array}$ & $\begin{array}{l}\text { This step encourages the inventor to solve the problem using } \\
\text { the inventive standards; however, we decided to skip the step } \\
\text { so that we can continue defining the problem in a broader } \\
\text { context at this stage, and can solve the problem later. }\end{array}$ \\
\hline $\begin{array}{l}\text { Step-8: Define the } \\
\text { problem more } \\
\text { precisely using patent } \\
\text { information }\end{array}$ & $\begin{array}{l}\text { The most common problem-solving strategies described in } \\
\text { patents, on the internet, and by leading industries appear to } \\
\text { recommend a ban, rationing of usage, or increasing self- } \\
\text { awareness. } \\
\text { ("Beeminder," 2018, "Freedom: Internet, App and Website } \\
\text { Blocker," 2018, "The rise and rise of Sudoku | The } \\
\text { Independent," 2006; Montechi \& Russo, 2015; Wang, } \\
\text { Zhong, \& Shu, 2008; } \\
\text { Yeolekar \& Sharma, 2004) }\end{array}$ \\
\hline $\begin{array}{l}\text { Step 9: Use STC } \\
\text { operator (Size, Time, } \\
\text { Cost) }\end{array}$ & $\begin{array}{l}\text { The conclusions from this step were: - As the cost increases, } \\
\text { the parent has better control. } \\
\text { - As the number of apps on the device increases, the }\end{array}$ \\
\hline
\end{tabular}


learning/engagement/discovery opportunities for the child improve.

The main elements in the contradiction model derived from these steps were the number of apps and the feeling of loss of control for the parent. Our analysis from this part is explained in Section 5. The input for the next part (Part-1) was the conflict among these variables - the number of apps, parental control, and the learning/engagement/discovery of the child interacting with the app.

\subsection{Part 1: Analyzing the Problem}

Part-1-Step-1: Formulate the mini-problem.

The main purpose of this step in Part-1 is to understand the conflict or contradiction from the perspective of the system.

The system is defined in the following manner:

A technical system for <playing mobile games $><$ during the child's non-school time > includes <device, child's eyes, child's thumbs, child's mind, app, WiFi>. The contradictions in this problem are described as follows:

Technical contradiction 1 (TC-1): if many apps are used, the child is exploring/learning/discovering new apps, but the parents cannot control the apps downloaded/installed/used.

Technical contradiction 2 (TC-2): if few apps are used, the child's parents can control the apps downloaded/installed/used, but the child's learning/engagement/discovery with respect to new apps may be limited.

We summarized the objective of this study in the following manner:

It is necessary, with minimum changes to the system, to < [let] the child explore/learn/discover new apps> while < the parents [can] control the apps downloaded/installed/used>.

Part-1-Step-2: Define the conflicting elements.

Based on the description of the problem in Subsection 3.2, the conflicting elements are defined using the terms product and tool. The product is defined as the element that needs to be processed, and the tool is the element that directly interacts with the product. Product: Child's mind, eyes, and thumbs Tool: App and device

Part-1-Step-3: Describe graphic models for technical contradictions. (Fig. 2) 


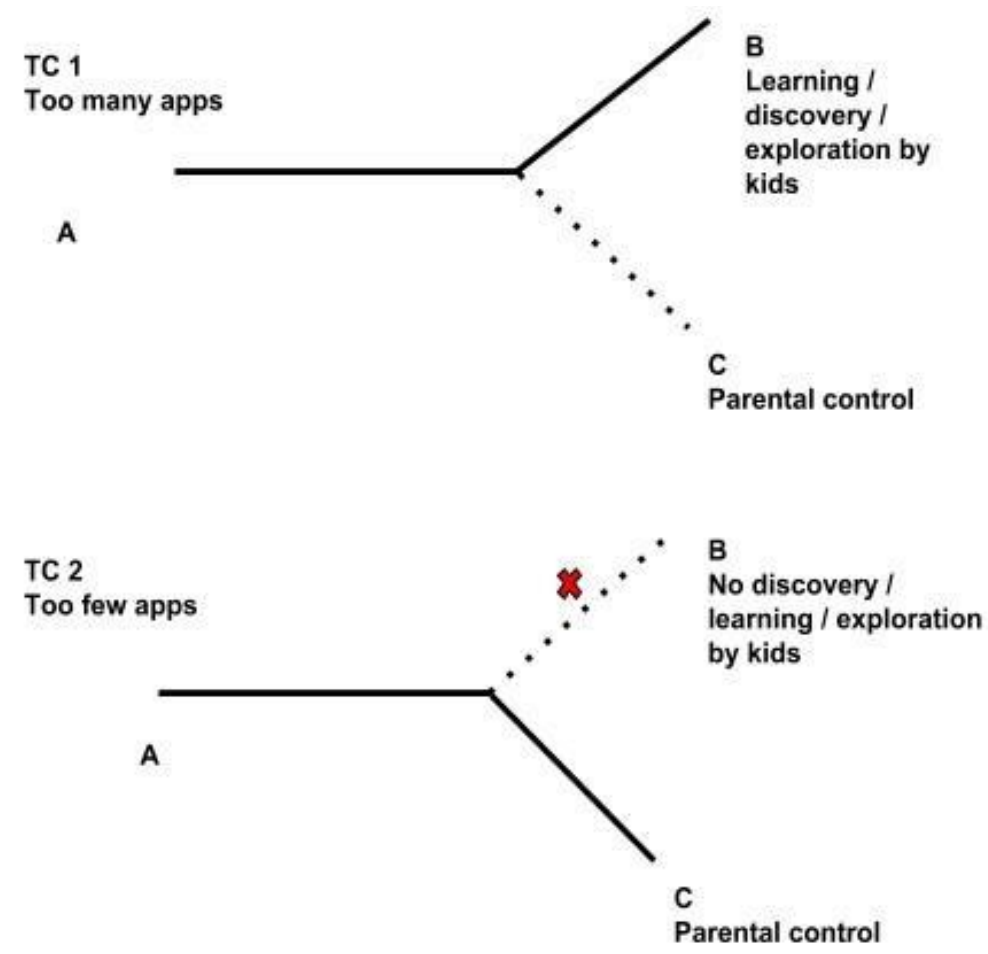

Fig. 2. The contradiction described in the Step-2 define the conflicting elements is depicted in graphical form

\section{Part-1-Step-4: Select a graphic model for further analysis.}

In this step, we chose one contradiction from TC- 1 and TC-2 described earlier. Given the purpose of the technical system $<$ playing mobile games $><$ during the child's nonschool time >, we decided to pursue TC- 1 . TC-1 provides options for the child to explore, and hence, it is deemed as an efficient system to enable playing games.

TC-1: if many apps are used, the child is exploring/learning/discovering new apps, but the parents cannot control the apps downloaded/installed/used.

\section{Part-1-Step-5: Intensify the conflict.}

Intensifying the conflict implies that we make the problem worse by considering the extreme state of elements. In this case, the chosen parameter was the number of apps on the mobile device. If we removed all parental control and made all apps accessible on the Google Play Store for the child to install, the original problem statement would be intensified.

Part-1-Step-6: Describe the problem model.

Given the intensification of the conflict from Section Part-1-Step-5: Intensify the conflict., the conflicting pair was:

Product: Child's mind, thumbs, and eyes 
Tool: App and Device

The intensified conflict definition now read: The parents cannot control the apps that the children play when the children have access to all the apps in the play store.

Therefore, in order to solve the problem, one must find the X-element that will maintain parental control over the types of apps that the child uses, while allowing complete access to all apps.

\section{TC 1 intensified}

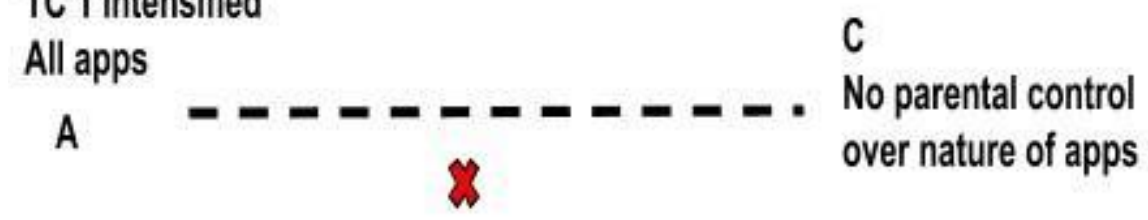

Fig. 3. A modified version of the contradiction in Fig. 1 to represent the intensified conflict definition. The "X" represents the unknown solution.

From our analysis of the problem, the X-element (Fig. 3) should satisfy the following conditions:

- Will maintain access to all apps (discoverability of apps for the child)

- Will maintain parental control over the apps being installed Part-1-

\section{Step-7: Apply the inventive standards.}

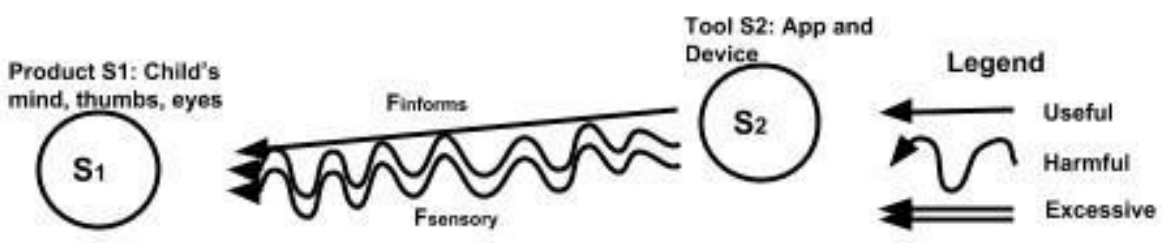

Fig. 4. Substance-Field (Su-Field) representation of the conflict between the product (child's mind, thumbs, and eyes) and the tool (app and device). The double line ( $\mathrm{F}_{\text {sensory }}$ ) represents excessive interaction between $S_{1}$ (product) and $S_{2}$ (tool). The wavy nature of $F_{\text {sensory }}$ indicates the harm caused to $S_{1}$ by $S_{2}$. The useful interaction is Finforms, which is represented by a solid line

First, we described the problem using a Su-Field model (Fig. 4). Then, we applied inventive standards to generate several partial concepts or technical solutions. We describe one such partial concept as an illustration of the application.

Inventive Standard 1.2.1: Separate new app discovery in time and space. We could visualize a potential technical solution as:

A walk-in booth for apps (a physical Google Play Store) that allows the child to explore before deciding to install an app. Parental permission is necessary to help the child complete the installation of highly addictive apps.

A helper class from the inventive standards (5.1.1.6) was applied to reduce the complexity of the above technical solution. After the application of the class, our 
concept reduced to a virtual store on a dedicated device; this store would only allow exploration for a limited time period. The final installation would be performed on another device that the parent owned.

We proceeded to the next set of steps, Part-2: Analyzing the Problem Model.

\subsection{Part-2: Analyzing the Problem Model}

Using the 3 steps in this part, we determined the physical location (operational zone $(\mathrm{OZ})$ ) of the contradiction, the time (operational time (OT)) of the contradiction, and a list of resources available to solve the problem in the problem scenario.

The OZ is the screen with the "INSTALL" button and the subsequent "ACCEPT" button (Fig. 5). We used Google Play Store as reference.
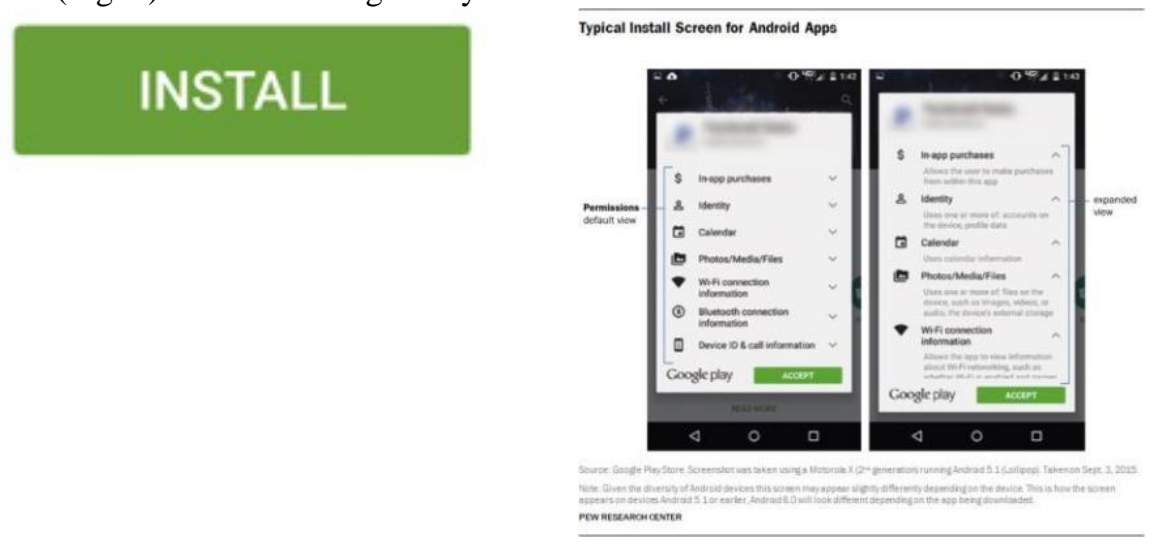

Fig. 5. The "INSTALL" and "ACCEPT" buttons are the regions where the conflict exists in the scenario of a child installing an app.

We observed the steps when a child installs an app. The steps were (the typical time for each step is within parentheses) (Kelley et al., 2012):

1. Searching/Browsing (>10 minutes)

2. Deciding (a few seconds)

3. Accepting permissions ( $<1$ second)

4. Beginning installation ( $\sim 2$ seconds after clicking the "Accept" button)

These steps are summarized in Fig. 6. " $t_{2}$ " is the time before conflict, and " $t_{1}$ " is the time of conflict or OT. $t_{l}$ is approximately 3 seconds. 


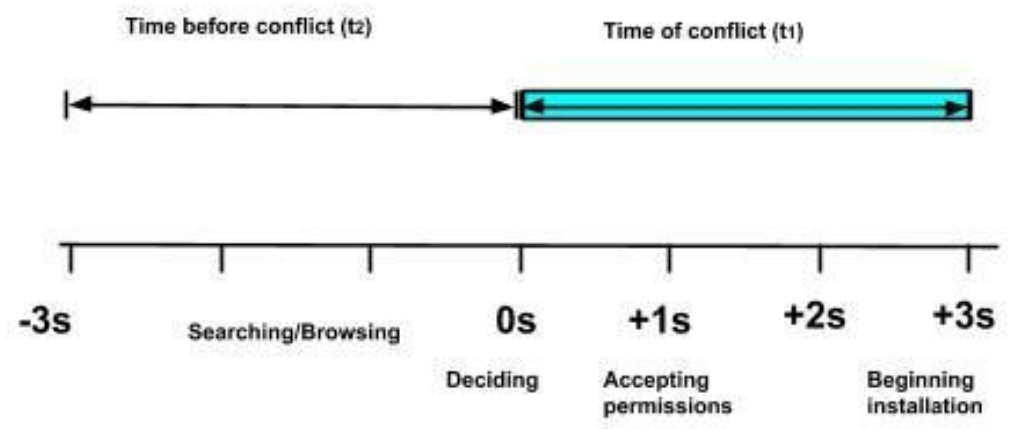

Fig. 6. Illustration of the operational time (OT) through a graphic representation of the steps in installing the game. $t_{l}$ is the time of conflict when the child has decided and has pressed the "INSTALL" button. This time also includes the pressing of the "ACCEPT" button. The time, $t_{2}$, before the conflict arises, is the time when the child is searching/browsing the store for apps of interest.

Step-3 defines the substance-field resources (SFR) of the ICT mobile device (internal resources), the environment in which the product and tool operate, and the supersystem (Table 3).

Table 3. Substance-Field Resources available to solve the contradiction defined in Part-1

\begin{tabular}{|l|l|l|}
\hline \multirow{2}{*}{ Internal } & Product & Child's thumbs, mind, eyes \\
\cline { 2 - 3 } & Tool & $\begin{array}{l}\text { device/app (accelerometer, } \\
\text { GPS, LED backlight, } \\
\text { capacitive touch, haptic) }\end{array}$ \\
\hline \multirow{2}{*}{$\begin{array}{l}\text { Resources } \\
\text { Environment }\end{array}$} & External to tool & $\begin{array}{l}\text { other apps, other devices, } \\
\text { WiFi/network signals, } \\
\text { cellphone signals, bluetooth }\end{array}$ \\
\cline { 2 - 3 } Supersystem & "Background" & Earth's magnetic field \\
\cline { 2 - 3 } & Waste materials & $\begin{array}{l}\text { heat from the device, old } \\
\text { installers, past profile info }\end{array}$ \\
\cline { 2 - 3 } & Very cheap resources & $\begin{array}{l}\text { friends, .apk files, } \\
\text { advertisements, points/credits } \\
\text { given at app level, favorite } \\
\text { toys/games/apps }\end{array}$ \\
\hline
\end{tabular}

The results from Part-2 will be used in Part-3: Defining the Ideal Final Result (IFR) and Physical Contradiction (PhC).

\subsection{Part-3: Defining the Ideal Final Result (IFR) and Physical Contradiction (PhC)}

The purpose of this part of ARIZ is to refine the contradiction by using the results from Part-2 (OT, OZ, and SFR). The steps have been carried out as described in the template 
in ARIZ-85c. After following the five steps in this part, the final IFR, which included a physical contradiction (Fig. 7), was:

The <color > of <the install button> on <the install screen> has to provide $<$ "permission denied" state> during the <time of installation of about 3 seconds $>$ and $<$ "permission granted" state> during <other times $>$.

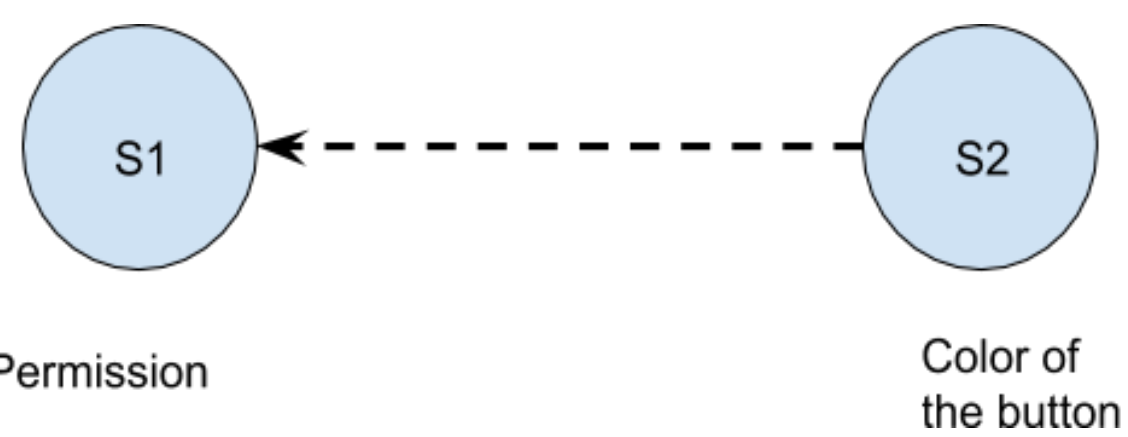

Fig. 7. Substance-Field diagram of the problem defined in Part-3 Defining the Ideal Final Result (IFR) and Physical Contradiction (PhC). Currently, the color of the button "is insufficient" to communicate the permission level to the user.

\section{Analysis and the solution concept}

Before performing ARIZ-based analysis, we built the system operator (SO). From the SO, we were able to determine the purpose (of the solution/situation to the user) and the viewpoint (of the parent/solver). The SO is represented in space and time. By analyzing the SO, we were able to derive the following trends:

a) PC Games were primarily played as an activity within the family ( 5 years ago). Now, the child has started playing mobile games with friends. This trend, when projected into the future ( 5 years hence), may result in virtual games being played with a larger interest group.

b) Earlier, the devices were static and bulky; now, they are light and mobile. The gaming experience is likely to move further away from home and is likely to be immersive in nature.

In our analysis in Part-0, we characterized the potential harm and benefit of using technology; this characterization can be used to judge the generated solution concept (Step-1). In Step-2, we chose the method prescribed in Design Thinking (Ulrich, 2011). This method combines the "5-Whys" approach for subsystem-level analysis and the "How might we..." approach for super system-level analysis. An example from the combined method is given below:

Problem: In what way might we want to reduce the screen time of the mobile devices/app?

Question: Why do these screens run for such a long time? 
Reason: The screens run for a long time since the mobile devices/apps run for a long time.

The questioning then proceeded to the next level. We narrowed down the "Why" questioning to 5 levels and the "How might we..." questioning to approximately 5 levels at the technological level.

From this approach, we deduced a user-level insight: the social circle influences a child's choice of device or game. This insight would not have emerged without the multi-level approach suggested in Design Thinking. This insight is also significant because his step determines the technical characteristics to be improved in the next step.

In Step-3, the decision to choose "In what way might we control the nature of apps that are downloaded?" was based on both objective and subjective factors. We considered objective factors (reserves of evolution of the system) and subjective factors (extent to which we, as problem solvers, were ready to change the system) selecting the problem for analysis. A preliminary interview that we conducted helped us conclude that this question may be the most effective starting point. However, the implication of the other levels derived from Step-2 could also be investigated.

In Step-1, Step-2, and Step-3, we considered only the qualitative characteristics; therefore, in Step-4 and Step-5, we considered the scale of the need for the invention. We also evaluated the quantitative characteristics of the need. The trend from the system operator and the quantitative characteristics suggested that mobile games may be replaced by immersive, and hence, more addictive augmented or virtual reality based gaming. The underlying problem statement may not change in spite of changes in the subsystem.

For the scale of the invention (Step-6), we considered the entire population of children between 10-14 years of age and projected the growth of this population to the span of the product development (typically 2 years). The size of the market is estimated to be about 635 million children in 2019-20 at an estimated growth rate of $1 \%$.

From our analysis of the problem using Step- 8 , we deduce that the perception of being distracted by online media is prevalent not only among parents who are anxious about their children, but also among adults worried about their own distraction. This anxiety is evident from the popularity (measured by the number of downloads) of the existing apps that allow media apps to be disabled. The thought experiments conducted by using the STC operator served as a precursor to defining the contradiction required in Part-1. The variables considered were: a) number of apps (size), b) time spent on device by the child (time), and c) cost of the app (cost). This exercise helped us ascertain the model of the contradiction of the problem.

The contradiction for further analysis was derived from the various steps applied in Part- 0 . We had considered the supersystem, the quantitative characteristics, and the models relevant to the problem.

After applying Part-1, we obtained an intensified contradiction that led us beyond the immediate problem context to investigate a more serious or extreme problem situation-What if the child is allowed access to all apps? 
The location and time of conflict, specified in Part-2, helped us document the specifics of the problem. In Part-3, we described the IFR by using a template wording. In the IFR definition, we used the time and location of conflict described in Part-2.

With the help of the IFR, we generated the final solution, which is described below:

Solution Concept: Install a control switch app that will send a one-time-password (OTP) to a mobile phone/email address (of the parents); this OTP can be used to proceed with the app installation. The control switch app cannot be uninstalled by the child. The rules were:

1. The OTP sent to parent for installation expires after a fixed time 2. To modify or uninstall the control switch app, another OTP is needed.

3. Analogy from the Fair Use Practice (FUP) of the internet service providers: if the number of hours of play per day exceeds a pre-determined value, the performance of the app/device slows down or degrades. (Using 1.1.3 Introducing an external Substance-Field)

This solution satisfies all the $\mathrm{X}$-element factors described by the analysis so far, and we believe that the next step is to build a prototype and test the concept.

\section{$5 \quad$ Implications and conclusions}

We have successfully applied a TRIZ-based algorithm to generate quasi-technical solutions for social science/behavioral problems.

We believe that the generated solutions are novel and that the implications are numerous, considering the different stakeholders involved in this global issue. Hence, we suggest implications for: 1) TRIZ practitioners in non-technical fields, 2) solution developers who build some of the novel solutions, generated through the application of TRIZ, and 3) large transnational companies that develop habit-forming applications, which may result in the pathological use of technologies.

TRIZ practitioners who help and train teams to apply the methodology are likely to succeed in novel solution generation when they limit the scope of application and the number of stakeholders involved in the problem. In our application, we limited the scope to children in the 10-14 age group and introduced controls that are administrable by the parents. Further, we limited our analysis to the OZ and OT of the install screen, and hence, derived solutions that could display the desired characteristics (as defined in earlier steps).

Solution developers are also stakeholders who need to be involved in the engineering/technical development, especially when solution concepts are quasitechnical in nature. From our own experience, consistent practice led to clarity in problem-solving when applying this methodology. In an organization, this type of practice can be an additional benefit of such an application, thus helping solution developers assimilate key method-specific knowledge that can be further diffused to a broader population within an organizational context. In addition, because of the origin of TRIZ in engineering and technological fields, the adoption by solution developers will likely be technical, which complements such non-technical field applications.

Finally, the current activism in the US by activist shareholders of Apple and Facebook, and regulatory efforts in the EU point to the broader responsibilities that 
these companies can shoulder in society rather than focusing merely on growth and profit. Such responsibilities accompany the opportunities for developing novel solution concepts generated from the application of TRIZ to social issues. If active developer communities are initiated and supported along with providing integration and testability of solutions on these platforms, both robustness and variety of solutions are likely to increase.

The solution concept has already been partially implemented in varying degrees on ICT device platforms. For example, iOS from Apple allows parental control at the application level with a layered authentication mechanism. Further, various applications perform monitoring or tracking without control feature requirements. This deficiency can be attributed to the nature of ownership of ICT devices that presumes a single user to be both the owner and controller, leaving no room for integrated platform level applications that can offer solution concepts to resolve the contradiction of having both exploration and control. Hence, a fork or a derivative work from the existing platform becomes necessary for such concept implementations.

\section{$6 \quad$ Future work}

The theoretical validation of TRIZ-based methods in non-technical fields cannot be built longitudinally without the commitment and review of the wider research community. Our contribution is specific to the problematic use of the internet or ICT devices, and we have utilized only a subset of the parts of ARIZ adopted. We believe that, in future, our work could be extended to further validate TRIZ through applications in other non-technical social issues of interest. Additionally, from a methodological perspective we relied on specific cases, but this approach can be extended with other rigorous methods. Finally, in the spirit of open source, publishing the application of methods along with practice notes from different fields will widen the diffusion of ARIZ.

\section{$7 \quad$ Acknowledgements}

We gratefully acknowledge the help from Anita Nagarajan for editing an earlier version of this paper and suggesting valuable changes. However, the authors alone are responsible for any deficiencies that may remain in the article.

This research work is self-sponsored. 


\section{References}

1) Altshuller, G. S. (1987). The History of ARIZ development. TRIZ. Simferopol. Retrieved from https://www.seecore.org/d/ariz_hist.pdf

2) Altshuller, G. S. (Genrikh S., Shulyak, L., \& Rodman, S. (1999). The innovation algorithm: TRIZ, systematic innovation and technical creativity. Technical Innovation Center. Retrieved from https://books.google.co.in/books?hl=en\&lr=\&id=qV3esXSZAEC\&oi=fnd\&pg=PR9\&dq=+altshuller\&ots=yGPcQNY7Zv\&sig= DLrHbpMwjaJdcA0vY6m1BDuVs2g\#v=onepage \&q=altshuller\&f=false

3) Bavelier, D., Green, C. S., \& Dye, M. W. G. (2010). Children, Wired: For Better and for Worse. Neuron. https://doi.org/10.1016/j.neuron.2010.08.035

4) Beeminder. (2018). Retrieved March 22, 2018, from https://www.beeminder.com/

5) Block, J. J. (2008). Issues for DSM-V: Internet addiction. American Journal of Psychiatry, 165(3), 306-307. https://doi.org/10.1176/appi.ajp.2007.07101556

6) Bozkurt, H., Coskun, M., Ayaydin, H., Adak, I., \& Zoroglu, S. S. (2013). Prevalence and patterns of psychiatric disorders in referred adolescents with Internet addiction. Psychiatry and Clinical Neurosciences, 67(5), 352-359. https://doi.org/10.1111/pcn.12065

7) Chai K-H, Zhang J, Tan K-C (2005) A TRIZ-Based Method for New Service Design. J Serv Res 8:48-66 . doi: 10.1177/1094670505276683

8) Chechurin, L. (2016). TRIZ in Science. Reviewing Indexed Publications. Procedia CIRP, 39, 156-165. https://doi.org/10.1016/j.procir.2016.01.182

9) Chechurin, L., \& Borgianni, Y. (2016). Understanding TRIZ through the review of top cited publications. Computers in Industry, 82, 119-134. https://doi.org/10.1016/j.compind.2016.06.002

10) Domb E (2003) TRIZ for Non-Technical Problem SolvingThe Triz Journal. In: triz-journal. https://triz-journal.com/triz-non-technical-problem-solving/. Accessed 10 Jul 2018

11) Freedom: Internet, App and Website Blocker. (2018). Retrieved March 22, 2018, from https://freedom.to/

12) Ilevbare, I. M., Probert, D., \& Phaal, R. (2013). A review of TRIZ, and its benefits and challenges in practice. Technovation. https://doi.org/10.1016/j.technovation.2012.11.003

13) Kawa, L. (2018). Two Major Apple Shareholders Push for Study of iPhone Addiction in Children - Bloomberg. Retrieved March 14, 2018, from https://www.bloomberg.com/news/articles/2018-01-08/jana-calperspushapple-to-study-iphone-addiction-in-children

14) Kelley, P. G., Consolvo, S., Cranor, L. F., Jung, J., Sadeh, N., \& Wetherall, D. (2012). A conundrum of permissions: installing applications on an android smartphone. In International Conference on Financial Cryptography and Data Security (pp. 68-79). Retrieved from 
https://pdfs.semanticscholar.org/761d/83c872ef314acf2915d41a7f49bbdeeec 5ee.pdf

15) Ko, C. H., Yen, J. Y., Yen, C. F., Chen, C. S., \& Chen, C. C. (2012, January). The association between Internet addiction and psychiatric disorder: A review of the literature. European Psychiatry. https://doi.org/10.1016/j.eurpsy.2010.04.011

16) Kucharavy, D. (2006). ARIZ: theory and practice. Retrieved March 31, 2018, from https://www.seecore.org/d/2006m6dk.pdf

17) Kumari, S., \& Ahuja, S. (2010). Video viewing and cognitive development in preadolescents. Social Science Computer Review, 28(2), 170-176. https://doi.org/10.1177/0894439309334815

18) Kuss, D. J., Griffiths, M. D., Karila, L., \& Billieux, J. (2014). Internet addiction: A systematic review of epidemiological research for the last decade. Current Pharmaceutical Design, 20(25), 1-27. https://doi.org/10.2174/13816128113199990617

19) Lips, M., Eppel, E., McRae, H., Starkey, L., Sylvester, A., Parore, P., \& Barlow, L. (2017). Understanding children's use and experience with digital technologies: final research report.

20) Montecchi, T., \& Russo, D. (2015). Knowledge based approach for formulating TRIZ contradictions. In Procedia Engineering (Vol. 131, pp. 451463). https://doi.org/10.1016/j.proeng.2015.12.440

21) Palaiologou, I. (2016). Children under five and digital technologies: implications for early years pedagogy. European Early Childhood Education Research Journal, 24(1), 5-24. https://doi.org/10.1080/1350293X.2014.929876

22) Schut, J. (2016). Using TRIZ in the Social Sciences: Possibilities and Limitations. In Research and Practice on the Theory of Inventive Problem Solving (TRIZ) (pp. 237-241). Cham: Springer International Publishing. https://doi.org/10.1007/978-3-319-31782-3_14

23) Sergi, K., Gatewood, R., Elder, A., \& Xu, J. (2017). Parental perspectives on children's use of portable digital devices. Behaviour \& Information Technology, 36(11), 1148-1161. https://doi.org/10.1080/0144929X.2017.1360941

24) Shaffer HJ (1996) Understanding the means and objects of addiction: Technology, the internet, and gambling. J Gambl Stud 12:461-469 . doi: 10.1007/BF01539189

25) Shaffer, H. J., Hall, M. N., \& Vander Bilt, J. (2000). Computer addiction: A critical consideration. American Journal of Orthopsychiatry, 70(2), 162-168. https://doi.org/10.1037/h0087741

26) Shapira, N. A., Lessig, M. C., Goldsmith, T. D., Szabo, S. T., Lazoritz, M., Gold, M. S., \& Stein, D. J. (2003). Problematic internet use: Proposed classification and diagnostic criteria. Depression and Anxiety, 17(4), 207-216. https://doi.org/10.1002/da.10094

27) Sharma, P., Khanna, R. R., \& Bhatnagar, V. (2016). A Literature Survey and Classification Framework of TRIZ Methodology. 2016 Second International 
Conference on Computational Intelligence \& Communication Technology (CICT), 516-522. https://doi.org/10.1109/CICT.2016.108

28) The rise and rise of Sudoku | The Independent. (2006). Retrieved March 22 , 2018, from https://www.independent.co.uk/news/uk/this-britain/the-riseandrise-of-sudoku-5336007.html

29) Tiku, N. (2018). Facebook, Twitter Under FireInvestors Join Calls for Facebook, Twitter to Take More Responsibility From Activist Investors |WIRED. Retrieved March 14, 2018, from https://www.wired.com/story/investors-join-calls-for-facebook-twittertotake-more-responsibility/

30) Ulrich KT (2011) Design: Creation of Artifacts in Society. SSRN Electron J 145 . doi: $10.2139 / \mathrm{ssrn} .1951106$

31) United Nations Department of Economic and Social Affairs, P. D. (2017). Profiles of Ageing 2017. Retrieved from https://population.un.org/ProfilesOfAgeing2017/index.html

32) Wang, J., Zhong, J., \& Shu, Q. (2008, September 9). Method and system for limiting time for online game users, ppp server, and online game server. Retrieved from https://patents.google.com/patent/US20090011830A1/en

33) Yeolekar, M., \& Sharma, A. (2004). Use of mobile phones in ICU - Why not ban? Journal of the Association of Physicians of India, 52, 312-313.

34) Zlotin, B., Zusman, A., Kaplan, L., Visnepolschi, S., Proseanic, V., \& Malkin, S. (1999). TRIZ beyond technology: The theory and practice of applying TRIZ to nontechnical areas. Detroit: Ideation. Retrieved June, 2, 2005. Retrieved from https://pdfs.semanticscholar.org/c7d7/653f22df8c3e448b261e2a45a54c2b13 7cb6.pdf 